\title{
A rhodium(I) dicarbonyl complex with a redox-active ferrocenyl phosphine- NHC ligand: enhanced reactivity of the metal centre through ferrocene oxidation
}

\author{
Nathalie Debono, ${ }^{\mathrm{a}, \mathrm{b}}$ Jean-Claude Daran, ${ }^{\mathrm{a}, \mathrm{b}}$ Rinaldo Poli ${ }^{\mathrm{a}, \mathrm{b}, \mathrm{c}}$ and Agnès Labande ${ }^{*, a, b}$ \\ a. CNRS, LCC (Laboratoire de Chimie de Coordination), 205 route de Narbonne, BP 44099, F-31077 Toulouse \\ Cedex 4, France. E-mail: agnes.labande@Icc-toulouse.fr; Fax: (+33) 561553003; Tel: (+33) 561333158 \\ b. Université de Toulouse, UPS, INPT, F-31077 Toulouse Cedex 4, France \\ c. Institut Universitaire de France, 103 bd Saint-Michel, F-75005 Paris, France
}

This paper is dedicated to Professor Claude Lapinte on the occasion of his retirement.

\begin{abstract}
A rhodium(I) dicarbonyl complex bearing a bidentate ferrocenyl phosphine-NHC ligand has been synthesized and characterized by NMR, IR spectroscopy, mass spectrometry and X-Ray diffraction methods. Its behaviour towards oxidation was investigated and revealed that changing the oxidation state of ferrocene can significantly modify the electron density at rhodium. Oxidation of the rhodium(I) dicarbonyl complex in acetonitrile furnished an airstable rhodium(III) complex, stabilized by acetonitrile molecules and with an interesting $\mathrm{C}-\mathrm{H}$ bond activation at ferrocene. This new rhodium(III) complex is active for the hydrosilylation of acetophenone and its derivatives.
\end{abstract}

\section{Introduction}

Wrighton et al. first demonstrated in the early 1990s that fine tuning of the electronic properties of a metal complex could be achieved by the introduction of redox-active ligands, as they were able to enhance the reactivity of a carbonyl ligand coordinated to rhenium towards nucleophiles by changing the oxidation state of cobaltocene [1]. In the area of catalysis, Mirkin also described the use of hemilabile redox-active ligands that presented charge-dependent behaviour [2]. Later, Gibson and Long showed that they could reversibly modulate the activity of a titanium polymerisation catalyst with the help of a substitutionally inert, redox-active ligand [3]. More recent examples include the work of Bielawski [4-6], Diaconescu $[7,8]$ and Plenio $[9,10]$.

Many redox-active groups have been incorporated, such as the ubiquitous ferrocene [2-5,913], or other metallocenes [1,14], quinone [6], terthienyl [15], amidophenolates [16], etc. However, it was only recently that the redox properties of $\mathrm{N}$-heterocyclic carbenes (NHC) bearing electroactive groups were exploited in catalysis. The NHC can either be in direct electronic communication with the electroactive moiety (ferrocene [5], quinone [6]), or 
simply act as an ancillary ligand or "anchor" to guarantee the stability of the complex whatever the oxidation state of the electroactive component [9].

Our group has a strong interest in the chemistry and catalytic activity of functionalised $\mathrm{N}$ heterocyclic carbene complexes [17-21]. We have recently investigated the behaviour of a 1,5-cyclooctadiene (COD) rhodium(I) complex bearing a ferrocenyl phosphine-NHC ligand, 1, towards oxidation (figure 1) [21]. We have been able to demonstrate that iron oxidation has dramatic consequences on the reactivity of the rhodium complex, and we then wished to extend this work to a similar rhodium(I) complex possessing carbonyl ligands in place of COD. The results of these studies are described here.

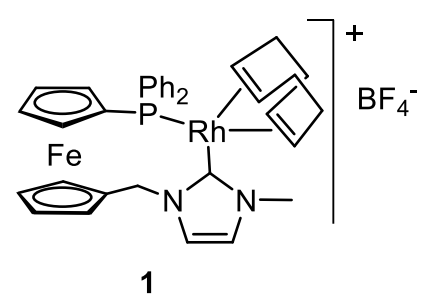

Figure 1. Rhodium(I) complex 1 with redox-active ferrocenyl phosphine-NHC ligand.

\section{Experimental}

\section{General considerations}

All manipulations were carried out under an inert atmosphere of dry argon by using vacuum line and Schlenk tube techniques. Solvents for all syntheses were dried and degassed by standard methods before use, unless otherwise stated.

The 1D- and 2D-NMR spectra were recorded on Bruker AV500 and AV400 spectrometers. ${ }^{1} \mathrm{H}$ and ${ }^{13} \mathrm{C}$ chemicals shifts $(\delta)$ are given in ppm (the residual peak of deuterated solvents was used as reference). ${ }^{31} \mathrm{P}$ chemicals shifts are reported in ppm. Peaks are labelled as singlet (s), doublet $(\mathrm{d})$, triplet $(\mathrm{t})$, multiplet $(\mathrm{m})$ and broad $(\mathrm{br})$. The proton and carbon assignment were performed by COSY, HSQC, ${ }^{1} \mathrm{H}_{-}{ }^{13} \mathrm{C} \mathrm{HMBC},{ }^{1} \mathrm{H}_{-}{ }^{31} \mathrm{P} \mathrm{HMBC}$ experiments. The IR spectra were acquired on a Bruker Alpha-P spectrometer equipped with an ATR module (compound 2) or Perkin-Elmer Spectrum 100 FT-IR with an ATR module (compound 3). The MS spectra were obtained from the mass spectrometry service of the Paul Sabatier University. The cyclic voltammetry (CV) experiment was carried out with a PGSTAT-302N potentiostat (Metrohm) at $25^{\circ} \mathrm{C}$ using a Pt disk working electrode, a Pt wire counter electrode and a saturated calomel reference electrode (SCE); a $0.1 \mathrm{M} n-\mathrm{Bu}_{4} \mathrm{BF}_{4}$ solution was used as the supporting electrolyte. The solution used during the electrochemical study was typically $10^{-3} \mathrm{M}$ in rhodium compound. All electrochemical data are referenced versus ferrocene (in our hands, $\mathrm{E}^{\circ}\left[\mathrm{FcH} / \mathrm{FcH}^{+}\right]=0.54 \mathrm{~V} / \mathrm{SCE}$ in $\left.\mathrm{CH}_{2} \mathrm{Cl}_{2} / n-\mathrm{Bu}_{4} \mathrm{BF}_{4}, 0.1 \mathrm{~V} . \mathrm{s}^{-1}, 25^{\circ} \mathrm{C}\right)$. 
The rhodium(I) complex 1 [17] and thianthrenium tetrafluoroborate [Th][BF 4 [22] were prepared according to previously reported procedures.

\author{
Abbreviations \\ $C p^{\mathrm{P}}$ : cyclopentadienyl ring with the $\mathrm{PPh}_{2}$ substituent. \\ $\mathrm{Cp}^{\mathrm{C}}$ : cyclopentadienyl ring with the NHC substituent. \\ Fc: ferrocenyl. \\ Im: imidazol-2-ylidene. \\ L: ferrocenyl phosphine-NHC ligand.
}

\title{
Syntheses
}

\section{$\underline{\mathrm{Rh}(\mathrm{CO})}{ }_{2}\left(\mathrm{~L}^{2}\right]^{+} \mathrm{BF}_{4}^{-}(\mathbf{2})$}

$\mathrm{CO}$ was bubbled through a solution of complex 1 (50 mg, 7.0 $10^{-5}$ mole) in $\mathrm{CH}_{2} \mathrm{Cl}_{2}$ (30 mL) for 2h. After partial solvent evaporation, a yellow solid was obtained by precipitation with pentane. The solution was filtered off and the solid was washed twice with pentane to remove the 1,5-cyclooctadiene, then dried in vacuo. The solid was obtained as a yellow powder (42 mg, 91\%). IR (ATR): 2085 (s), 2029 (s) cm-1 ( $\left.v_{\mathrm{C}=0}\right)$. Occasionally, isolated samples of the product obtained from incomplete carbonylations gave a spectrum featuring a third $v_{\mathrm{C}=0}$ vibration at $1997(\mathrm{~m}) \mathrm{cm}^{-1}$, assigned to the monocarbonyl complex $(\leq 5 \%) ;{ }^{1} \mathrm{H} \mathrm{NMR}$ $\left(400.13 \mathrm{MHz}, \mathrm{CDCl}_{3}, 298 \mathrm{~K}\right): \delta 7.71\left(1 \mathrm{H}, \mathrm{d}, \mathrm{J}_{H H}=2.0 \mathrm{~Hz}, \mathrm{HC}=\mathrm{C} \mathrm{Im}\right), 7.63-7.53\left(6 \mathrm{H}, \mathrm{m}, \mathrm{PPh}_{2}\right)$, 7.50-7.45 (2H, m, PPh $), 7.43\left(1 \mathrm{H}, \mathrm{d}, \mathrm{J}_{H H}=2.0 \mathrm{~Hz}, \mathrm{HC}=\mathrm{C} \mathrm{Im}\right), 7.35-7.28\left(2 \mathrm{H}, \mathrm{m}, \mathrm{PPh}_{2}\right), 5.17(1 \mathrm{H}$, d, $\left.\mathrm{J}_{H H}=14.8 \mathrm{~Hz}, \mathrm{CH}_{2} \mathrm{Im}\right), 4.89\left(1 \mathrm{H}, \mathrm{d}, \mathrm{J}_{H H}=15.2 \mathrm{~Hz}, \mathrm{CH}_{2} \mathrm{Im}\right), 4.70\left(1 \mathrm{H}, \mathrm{m}, \mathrm{Cp}^{\mathrm{C}}\right), 4.61(1 \mathrm{H}, \mathrm{m}$, $\left.C p^{\mathrm{P}}\right), 4.57\left(1 \mathrm{H}, \mathrm{m}, \mathrm{Cp}^{\mathrm{C}}\right), 4.40\left(1 \mathrm{H}, \mathrm{m}, \mathrm{Cp}^{\mathrm{P}}\right), 4.28\left(1 \mathrm{H}, \mathrm{m}, \mathrm{Cp} \mathrm{p}^{\mathrm{C}}\right), 4.18\left(1 \mathrm{H}, \mathrm{m}, \mathrm{Cp} \mathrm{p}^{\mathrm{C}}\right), 3.47(1 \mathrm{H}, \mathrm{br} \mathrm{s}$, $\left.\mathrm{Cp}^{\mathrm{P}}\right), 3.25\left(3 \mathrm{H}, \mathrm{s}, \mathrm{CH}_{3}\right), 2.51\left(1 \mathrm{H}, \mathrm{br} \mathrm{s}, \mathrm{Cp}^{\mathrm{P}}\right) .{ }^{13} \mathrm{C} \mathrm{NMR}\left(100.62 \mathrm{MHz}, \mathrm{CDCl}_{3}, 298 \mathrm{~K}\right): \delta 186.7$ (dd, $\left.\mathrm{J}_{R h C}=55.7 \mathrm{~Hz}, \mathrm{~J}_{P C}=16 \mathrm{~Hz}, \mathrm{CO}\right), 181.8\left(\mathrm{dd}, \mathrm{J}_{R h C}=61.2 \mathrm{~Hz}, \mathrm{~J}_{P C}=102.3 \mathrm{~Hz}, \mathrm{CO}\right), 165.9\left(\mathrm{dd}, \mathrm{J}_{R h C}=\right.$ $\left.16.2 \mathrm{~Hz}, \mathrm{~J}_{P C}=42.1 \mathrm{~Hz}, C_{\text {carbene }}\right), 133.4\left(\mathrm{~d}, \mathrm{~J}_{P C}=12.5 \mathrm{~Hz}, C_{\mathrm{PPh} 2}\right), 132.7$ (d, J $\mathrm{J}_{P C}=12.4 \mathrm{~Hz}, \mathrm{CH}_{\mathrm{PPh} 2}$ ), 132.5 (quat $C_{P P h 2}$ ), $131.9\left(\mathrm{dd}, \mathrm{J}_{R h C}=2.0 \mathrm{~Hz}, \mathrm{~J}_{P C}=10.0 \mathrm{~Hz}, C_{\mathrm{PPh}}\right.$ ), 131.1 (d, $\mathrm{J}_{P C}=46.7 \mathrm{~Hz}$, quat $\left.C_{P P h 2}\right), 129.6\left(d, J_{P C}=10.5 \mathrm{~Hz}, C_{P P h 2}\right), 129.0\left(d, J_{P C}=10.8 \mathrm{~Hz}, C_{P P h 2}\right), 125.6(2 * C=C \mathrm{Im}), 88.0$ (quat $\mathrm{Cp}^{\mathrm{C}}$ ), $75.1\left(\mathrm{~d}, \mathrm{~J}_{P C}=7.7 \mathrm{~Hz}, \mathrm{Cp}^{\mathrm{P}}\right), 74.4\left(\mathrm{Cp}^{\mathrm{C}}\right), 73.3\left(\mathrm{~d}, \mathrm{~J}_{P C}=7.5 \mathrm{~Hz}, \mathrm{Cp}^{\mathrm{P}}\right), 72.8\left(\mathrm{~d}, \mathrm{~J}_{P C}=14.4\right.$ $\left.\mathrm{Hz}, C p^{\mathrm{P}}\right), 72.0\left(\mathrm{~d}, \mathrm{~J}_{P C}=6.6 \mathrm{~Hz}, \mathrm{Cp}^{\mathrm{P}}\right), 70.1\left(\mathrm{Cp}^{\mathrm{C}}\right), 69.5\left(\mathrm{Cp}^{\mathrm{C}}\right), 68.7\left(\mathrm{Cp}^{\mathrm{C}}\right), 68.4\left(\mathrm{~d}, \mathrm{~J}_{P C}=60.1 \mathrm{~Hz}\right.$, quat $\left.\mathrm{Cp}^{\mathrm{P}}\right), 49.0\left(\mathrm{CH}_{2} \mathrm{Im}\right), 37.6\left(\mathrm{CH}_{3} \mathrm{Im}\right) .{ }^{31} \mathrm{P} \mathrm{NMR}\left(161.98 \mathrm{MHz}, \mathrm{CDCl}_{3}, 298 \mathrm{~K}\right): \delta 19.98\left(\mathrm{~d}, \mathrm{~J}_{R h P}=132\right.$ $\mathrm{Hz}$ ). MS (ESI): m/z 595 [M-CO] (11), 384 [M- $\mathrm{C}_{6} \mathrm{H}_{4} \mathrm{~N}_{2} \mathrm{O}_{2} \mathrm{Rh}$ ] (96). HRMS (ES+): calcd for $\mathrm{C}_{29} \mathrm{H}_{25} \mathrm{FeN}_{2} \mathrm{O}_{2} \mathrm{PRh}$ 623.0058; found 623.0061.

\section{Oxidation of $\left[\mathrm{Rh}(\mathrm{CO})_{2}(\mathrm{~L})\right]^{+} \mathrm{BF}_{4}^{-}(2)$ in $\mathrm{CH}_{2} \mathrm{Cl}_{2}$}


In a glovebox, $\mathrm{AgBF}_{4}(10 \mathrm{mg}, 0.049 \mathrm{mmol}, 1.5$ equiv.) was added, as a solid, to a solution of complex 2 (23 mg, $0.033 \mathrm{mmol}$ ) in $\mathrm{CH}_{2} \mathrm{Cl}_{2}(3 \mathrm{~mL})$. The solution turned from yellow to deep green in a few seconds. Stirring was stopped to allow the silver precipitate to settle and an aliquot of the solution was deposited on the IR cell. After evaporation of the solvent, the green solid was analysed: IR (ATR) 2097 (s), 2045 (s) $\mathrm{cm}^{-1}\left(v_{\mathrm{c}=0}\right)$.

\section{Oxidation of $\left[\mathrm{Rh}(\mathrm{CO})_{2}(\mathrm{~L})\right]^{+} \mathrm{BF}_{4}^{-}(2)$ in $\mathrm{MeCN}$ : generation of $\left[\mathrm{Rh}\left(\mathrm{CH}_{3} \mathrm{CN}\right)_{3}(\mathrm{~L})\right]\left(\mathrm{BF}_{4}\right)_{2}(3)$}

A solution of thianthrenium tetrafluoroborate $\left(27 \mathrm{mg}, 8.9 \cdot 10^{-5}\right.$ mole, 1.5 equiv.) in $\mathrm{CH}_{3} \mathrm{CN}$ $\left(2.5 \mathrm{~mL}\right.$ ) was added dropwise to a solution of 2 (42 mg, 5.9.10-5 mole, 1 equiv.) in $\mathrm{CH}_{3} \mathrm{CN}$ (5 $\mathrm{mL}$ ). The mixture was stirred for $10 \mathrm{~min}$ at room temperature and then the solvent was evaporated in vacuo. The complex was precipitated with a $\mathrm{CH}_{3} \mathrm{CN} / \mathrm{Et}_{2} \mathrm{O}(1 / 9)$ mixture several times until the solution was colourless, then taken up into $\mathrm{CH}_{3} \mathrm{CN}$ and left standing for $48 \mathrm{~h}$. The solvent was evaporated in vacuo to give $\mathbf{3}$ as an orange solid (38.8 $\mathrm{mg}, 76 \%)$. IR (ATR) $V_{\text {max }} / \mathrm{cm}^{-1} 2322,2293$ and $2252(\mathrm{w})\left(\mathrm{C} \equiv \mathrm{N}_{\text {str. }}\right) ; 1474,1436$ and $1405(\mathrm{w} / \mathrm{m})\left(\mathrm{C}=\mathrm{C}_{\text {str. }}\right) ; 1051-999$ (vs) $\left(\mathrm{BF}_{4}\right) ; 747,696$ and $684(\mathrm{~m} / \mathrm{s})\left(\mathrm{C}-\mathrm{H}_{\text {bend. }}\right)$. ${ }^{1} \mathrm{H}$ NMR $\left(500.33 \mathrm{MHz}, \mathrm{CD}_{3} \mathrm{CN}, 228 \mathrm{~K}\right): \delta 7.65-$ 7.55 (3H, m, PPh $), 7.53-7.46\left(4 \mathrm{H}, \mathrm{m}, \mathrm{HC}=\mathrm{C} \mathrm{Im}+\mathrm{PPh}_{2}\right), 7.43-7.40\left(2 \mathrm{H}, \mathrm{m}, \mathrm{PPh}_{2}\right), 7.20(1 \mathrm{H}, \mathrm{s}$, $H C=C \operatorname{Im}), 7.11\left(2 \mathrm{H}, \mathrm{dd}, \mathrm{J}_{H H}=11.5 \mathrm{~Hz}, \mathrm{~J}_{H P}=7.5 \mathrm{~Hz}, \mathrm{PPh}_{2}\right), 5.63\left(1 \mathrm{H}, \mathrm{br} \mathrm{s}, \mathrm{Cp}^{\mathrm{P}}\right), 4.89\left(1 \mathrm{H}, \mathrm{d}, \mathrm{J}_{H H}=\right.$ $\left.16.1 \mathrm{~Hz}, \mathrm{CH}_{2} \mathrm{Im}\right), 4.73-4.66\left(4 \mathrm{H}, \mathrm{m}, \mathrm{Cp}^{\mathrm{C}}+2 \times \mathrm{Cp}^{\mathrm{P}}+\mathrm{CH}_{2} \mathrm{Im}\right), 4.58\left(1 \mathrm{H}, \mathrm{s}, \mathrm{Cp}^{\mathrm{C}}\right), 4.40\left(1 \mathrm{H}, \mathrm{s}, \mathrm{Cp}^{\mathrm{P}}\right)$, $4.18\left(1 \mathrm{H}, \mathrm{s}, \mathrm{Cp}^{\mathrm{C}}\right), 3.98\left(3 \mathrm{H}, \mathrm{s}, \mathrm{CH}_{3}\right) .{ }^{13} \mathrm{C} \mathrm{NMR}\left(125.82 \mathrm{MHz}, \mathrm{CD}_{3} \mathrm{CN}, 228 \mathrm{~K}\right): \delta 147.2\left(\mathrm{dd}, \mathrm{J}_{R h C}=\right.$ $\left.47.2 \mathrm{~Hz}, \mathrm{~J}_{P C}=11.4 \mathrm{~Hz}, C_{\text {carbene }}\right), 133.1-132.6\left(\mathrm{~m}, 2 \times o-\mathrm{CH}_{\mathrm{PPh} 2}+p-\mathrm{CH}_{\mathrm{PPh} 2}\right), 132.0$ (d, JPC $=9.8 \mathrm{~Hz}, 2$ $\left.x o-C_{P P h 2}\right), 131.3\left(d, J_{P C}=2.6 \mathrm{~Hz}, p-C H_{P P h 2}\right), 129.6\left(d, J_{P C}=10.9 \mathrm{~Hz}, 2 \times m-C_{P P h 2}\right), 128.5$ (d, JPC $=$ $\left.10.7 \mathrm{~Hz}, 2 \times \mathrm{m}-\mathrm{CH}_{\mathrm{PPh} 2}\right), 128.0\left(\mathrm{~d}, \mathrm{~J}_{P C}=52.2 \mathrm{~Hz}\right.$, quat $\left.C_{\mathrm{PPh} 2}\right), 126.3(\mathrm{C}=\mathrm{C} \mathrm{Im}), 124.1$ (C=C Im), 123.9 (quat $C$ ), 122.17 (d, quat $C$ ), 87.2 (br s, quat $C p^{C}$ ), $83.3\left(\mathrm{~d}, \mathrm{~J}_{P C}=9.1 \mathrm{~Hz}, C \mathrm{p}^{\mathrm{P}}\right.$ ), 77.1 (d, JPC $=$ 12.6 Hz, Cp $\left.{ }^{\mathrm{P}}\right), 75.3\left(\mathrm{Cp}^{\mathrm{C}}\right), 73.7\left(\mathrm{~d}, \mathrm{~J}_{P C}=7.2 \mathrm{~Hz}, \mathrm{Cp}^{\mathrm{P}}\right), 73.3\left(\mathrm{~d}, \mathrm{~J}_{P C}=6.9 \mathrm{~Hz}, \mathrm{Cp}^{\mathrm{P}}\right), 72.3\left(\mathrm{Cp}^{\mathrm{C}}\right), 71.4$ $\left(\mathrm{d}, \mathrm{J}_{P C}=65.8 \mathrm{~Hz}\right.$, quat $\left.\mathrm{Cp}^{\mathrm{P}}\right), 70.6\left(\mathrm{Cp}^{\mathrm{C}}\right), 50.4\left(\mathrm{CH}_{2} \mathrm{Im}\right), 39.1\left(\mathrm{CH}_{3}\right) .{ }^{31} \mathrm{P} \mathrm{NMR}(202.54 \mathrm{MHz}$, $\left.\mathrm{CD}_{3} \mathrm{CN}, 228 \mathrm{~K}\right): \delta 41.56\left(\mathrm{~d}, \mathrm{~J}_{R h P}=138 \mathrm{~Hz}\right)$.

General procedure for the hydrosilylation of acetophenone derivatives

The rhodium catalyst $\left(4 \cdot 10^{-6}\right.$ mole, 1 mol\%) was placed in a dry Schlenk tube under argon and THF $(0.2 \mathrm{~mL})$ and acetophenone $\left(3.9 \cdot 10^{-4}\right.$ mole, 1 equiv., $2.0 \mathrm{M}$ in THF) were added. Diphenylsilane (4.3.10-4 mole, 1.1 equiv.) was then added dropwise at room temperature and the resulting mixture was stirred for $17 \mathrm{~h}$. The solvent was concentrated in vacuo, the residue taken up into $\mathrm{CH}_{2} \mathrm{Cl}_{2}$ and $\mathrm{MeOH}(1 \mathrm{~mL})$ and stirred for $1 \mathrm{~h}$. $\mathrm{HCl}(2 \mathrm{M}, 1 \mathrm{~mL})$ was then added and the mixture was stirred for an additional hour. The phases were separated, the aqueous phase extracted with $\mathrm{CH}_{2} \mathrm{Cl}_{2}$ and the organic phases were dried $\left(\mathrm{MgSO}_{4}\right)$, filtered and concentrated in vacuo. The residue was analysed by ${ }^{1} \mathrm{H} N M R\left(\mathrm{CDCl}_{3}\right)$ and the conversions were calculated by integration and comparison of the characteristic signals of acetophenone $(\delta 2.63, \mathrm{~s}, 3 \mathrm{H})$ and 1-phenylethanol $(\delta 4.90, \mathrm{q}, 1 \mathrm{H})$.

Kinetic follow-up: the rhodium catalyst $\left(8 \cdot 10^{-6}\right.$ mole, 1 mol\%) was placed in a dry NMR tube under argon and $d_{8}$ THF $(0.4 \mathrm{~mL})$ and acetophenone $\left(7.9 \cdot 10^{-4}\right.$ mole, 1 equiv., $2.0 \mathrm{M}$ in THF) 
were added. Diphenylsilane $\left(8.7 \cdot 10^{-4}\right.$ mole, 1.1 equiv.) was then added dropwise at room temperature and the resulting mixture was shaken. The reaction mixture was analysed by ${ }^{1} \mathrm{H}$ NMR and the conversions were calculated by integration and comparison of the characteristic signals of acetophenone $(\delta 2.50, \mathrm{~s}, 3 \mathrm{H})$ and diphenyl(1-phenylethoxy) silane ( $\delta$ $1.53, \mathrm{~d}, 3 \mathrm{H})$.

\section{$X$-ray structural analyses}

A single crystal of compound $\mathbf{2}$ was mounted under inert perfluoropolyether at the tip of a glass fiber and cooled in the cryostream of an Oxford-Diffraction Xcalibur CCD diffractometer. The structure was solved by direct methods (SIR97 [23]) and refined by leastsquares procedures on $F^{2}$ using SHELXL-97 [24]. All $\mathrm{H}$ atoms attached to carbon were introduced in calculation in idealized positions and treated as riding models. The drawing of the molecules was realized with the help of ORTEP32 [25].

Crystal data for compound 2: yellow needles, $\mathrm{C}_{29} \mathrm{H}_{25} \mathrm{FeN}_{2} \mathrm{O}_{2} \mathrm{PRh} \cdot \mathrm{BF}_{4}, \mathrm{M}=710.05$, monoclinic, $a=9.5352(3), b=21.1742(7), c=13.8059$ (4) $\AA, \beta=101.32$ (3) ${ }^{\circ}, V=2734.97(15) \AA^{3}, T=180$ $\mathrm{K}$, space group $P 2_{1} / n$ (no 14), $Z=4, \mu(\mathrm{Mo}-K \alpha)=1.25 \mathrm{~mm}^{-1}, 29805$ reflections measured, 6010 unique $\left(R_{\text {int }}=0.032\right)$ which were used in all calculations, 5029 observed with $I \geq 2 \sigma(I), 389$ parameters, 17 restraints. The final $R$ and $w R\left(\mathrm{~F}^{2}\right)$ were 0.027 and 0.067 respectively(all data), GOF, 0.98.

\section{Results and discussion}

1. Synthesis and characterisation of the rhodium(I) dicarbonyl complex 2

The synthesis of the precursor rhodium complex 1 was reported in a previous work [17]. It is perfectly air stable and was not altered after several months of storage. Its ${ }^{31} \mathrm{P}$ NMR spectrum shows a doublet at $\delta 19.5\left(J_{\mathrm{Rh}-\mathrm{p}}=158 \mathrm{~Hz}\right)$, whereas the ${ }^{13} \mathrm{C}$ NMR spectrum shows a doublet of doublets situated at $\delta 176.9\left({ }^{1} J_{\mathrm{Rh}-\mathrm{C}}=49.7 \mathrm{~Hz},{ }^{2} J_{\mathrm{P}-\mathrm{C}}=15.5 \mathrm{~Hz}\right)$, typical of the $\mathrm{C} 2$ carbon in $\mathrm{Rh}(\mathrm{I}) \mathrm{NHC}$ complexes.

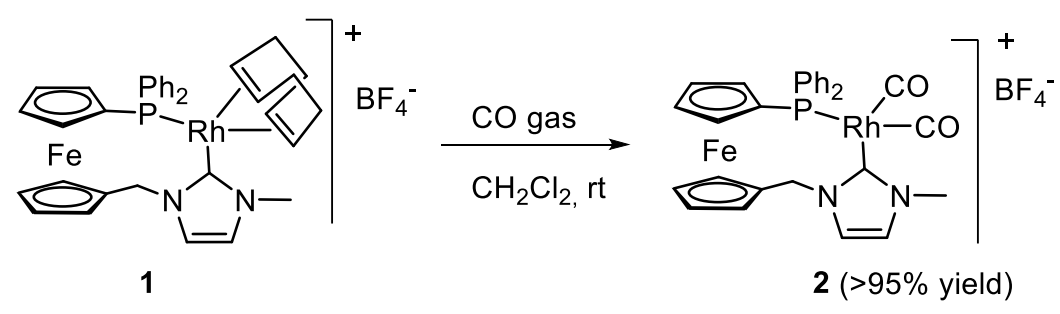

Scheme 1. Synthesis of rhodium(I) carbonyl complex 2.

The dicarbonyl complex 2 was prepared in quasi-quantitative yield, as verified by ${ }^{31} \mathrm{P}$ NMR monitoring, by bubbling $\mathrm{CO}$ gas through a solution of $\mathbf{1}$ in $\mathrm{CH}_{2} \mathrm{Cl}_{2}$ (scheme 1). As observed for other cationic $\mathrm{Rh}(\mathrm{I})$ complexes $[26,27]$, the resulting pale yellow solid is moderately stable in 
solution and decomposes in a few days when left in air. It is stable under argon in the solid form, however, and was fully characterised by conventional methods. Its ${ }^{31} \mathrm{P}$ NMR spectrum shows a doublet at $\delta 20.5$, with a smaller coupling constant to rhodium $\left(J_{\mathrm{Rh}-\mathrm{P}}=132 \mathrm{~Hz}\right)$ than that of complex 1 . The ${ }^{1} \mathrm{H}$ NMR spectrum revealed the disappearance of the COD proton signals, whereas typical signals for coordinated CO ligands were attributed in the ${ }^{13} \mathrm{C} N M R$ spectrum at $\delta 186.7$ (dd, ${ }^{1} \mathrm{~J}_{\mathrm{Rh}-\mathrm{C}}=55.7 \mathrm{~Hz},{ }^{2} \mathrm{~J}_{\mathrm{P}-\mathrm{C}}=16.0 \mathrm{~Hz}$, cis to $\mathrm{P}$ ) and 181.8 (dd, ${ }^{1} \mathrm{~J}_{\mathrm{Rh}-\mathrm{C}}=61.2 \mathrm{~Hz}$, ${ }^{2} J_{\mathrm{P}-\mathrm{C}}=102.3 \mathrm{~Hz}$, trans to P). The characteristic ${ }^{13} \mathrm{C}$ NMR signal of the $\mathrm{C} 2$ carbon (dd, $\delta 165.9$, ${ }^{1} J_{\mathrm{Rh}-\mathrm{C}}=42.1 \mathrm{~Hz},{ }^{2} J_{\mathrm{P}-\mathrm{C}}=16.2 \mathrm{~Hz}$ ) was found upfield compared to that of complex 1 , which is consistent with similar Rh(I) NHC complexes [26,28]. Finally infra-red spectroscopy, which is a very useful tool for the characterisation of carbonyl compounds, showed two intense bands for $v_{\text {co }}$ stretching frequencies at 2084 and $2029 \mathrm{~cm}^{-1}$, which are in accord with other cationic NHC-Rh complexes [26,27]. The presence of two bands of equal intensity is consistent with the expected cis arrangement of the two carbonyl groups.

X-ray quality crystals of $\mathbf{2}$ were obtained by slow diffusion of pentane into a $\mathrm{CH}_{2} \mathrm{Cl}_{2}$ solution of the complex under $1 \mathrm{~atm}$ of $\mathrm{CO}$, the diffraction analysis of which confirmed the expected structure (fig. 2), with a typical square-planar geometry about the rhodium atom. The structure does not present any unusual features. Selected bond lengths and angles are listed in Table 1. The carbene-rhodium and phosphorus-rhodium bond lengths are consistent with those measured in related $\mathrm{Rh}(\mathrm{I})-\mathrm{NHC}$ complexes $[28,29]$ and are similar, within errors, to those measured for the previously described Rh(I)-NHC COD complex 1 [17]. The Rh-carbonyl bond lengths are also within the expected range for this type of compounds.

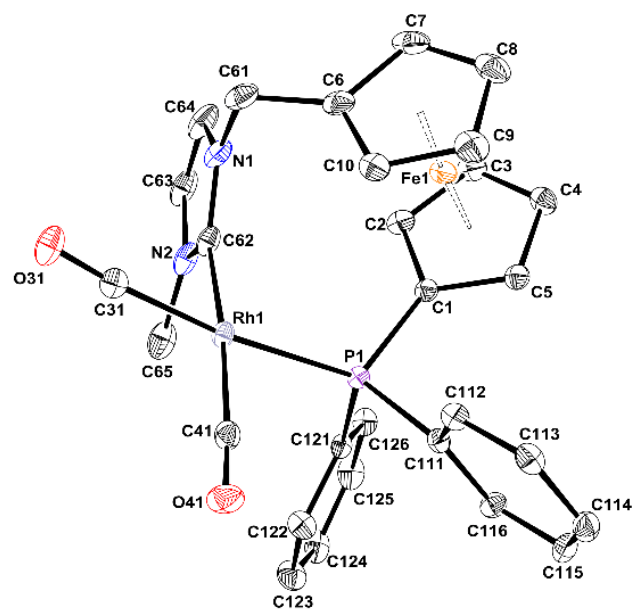

Figure 2. ORTEP representation of the cation in the dicarbonyl complex 2. Ellipsoids are shown at the $30 \%$ probability level. All hydrogen atoms are omitted for clarity. 
Table 1. Selected bond distances $(\AA)$ and angles $\left({ }^{\circ}\right)$ for the experimental structure of 2 and comparison with those of 1 [17].

\begin{tabular}{|l|l|l|}
\hline Bond & Complex 1 [17] & Complex 2 \\
\hline $\mathrm{Rh}(1)-\mathrm{C}(\mathrm{NHC})$ & $2.047(3)$ & $2.062(2)$ \\
\hline $\mathrm{Rh}(1)-\mathrm{P}(1)$ & $2.3345(8)$ & $2.3547(6)$ \\
\hline $\mathrm{Rh}(1)-\mathrm{C}(\mathrm{L})$ & $2.215(3), 2.231(3)$ & $1.901(3)$ \\
$(\mathbf{1}, \mathrm{L}=(\mathrm{COD}) ; \mathbf{2}, \mathrm{L}=\mathrm{CO})$ & $2.220(3), 2.217(3)$ & $1.886(3)$ \\
\hline $\mathrm{O}(31)-\mathrm{C}(31)$ & - & $1.124(3)$ \\
\hline $\mathrm{O}(41)-\mathrm{C}(41)$ & - & $1.128(3)$ \\
\hline Angle & & \\
\hline $\mathrm{C}(\mathrm{NHC})-\mathrm{Rh}(1)-\mathrm{P}(1)$ & $90.83(8)$ & $89.92(7)$ \\
\hline $\mathrm{C}(41)-\mathrm{Rh}(1)-\mathrm{P}(1)$ & - & $91.93(7)$ \\
\hline $\mathrm{C}(31)-\mathrm{Rh}(1)-\mathrm{C}(62)$ & - & $86.78(10)$ \\
\hline $\mathrm{C}(31)-\mathrm{Rh}(1)-\mathrm{C}(41)$ & - & $91.97(10)$ \\
\hline
\end{tabular}

\section{Oxidation studies}

The rhodium complex $\mathbf{2}$ was analysed by electrochemical methods. The cyclic voltammogram of 2 was recorded in $\mathrm{CH}_{2} \mathrm{Cl}_{2}$ (fig. 3). Similarly to that of complex 1 [21], the voltammogram shows a reversible redox wave for the ferrocene moiety at $E_{1 / 2}=0.43$ $\mathrm{V} /\left[\mathrm{FcH} / \mathrm{FcH}^{+}\right]$followed by an irreversible process at $1.06 \mathrm{~V} /\left[\mathrm{FcH} / \mathrm{FcH}^{+}\right]$, that could be assigned to the oxidation of $\mathrm{Rh}(\mathrm{I})$. By analogy with 1 , we can assume that the oxidation process at $0.43 \mathrm{~V}$ is a one-electron oxidation of ferrocene to ferrocenium.

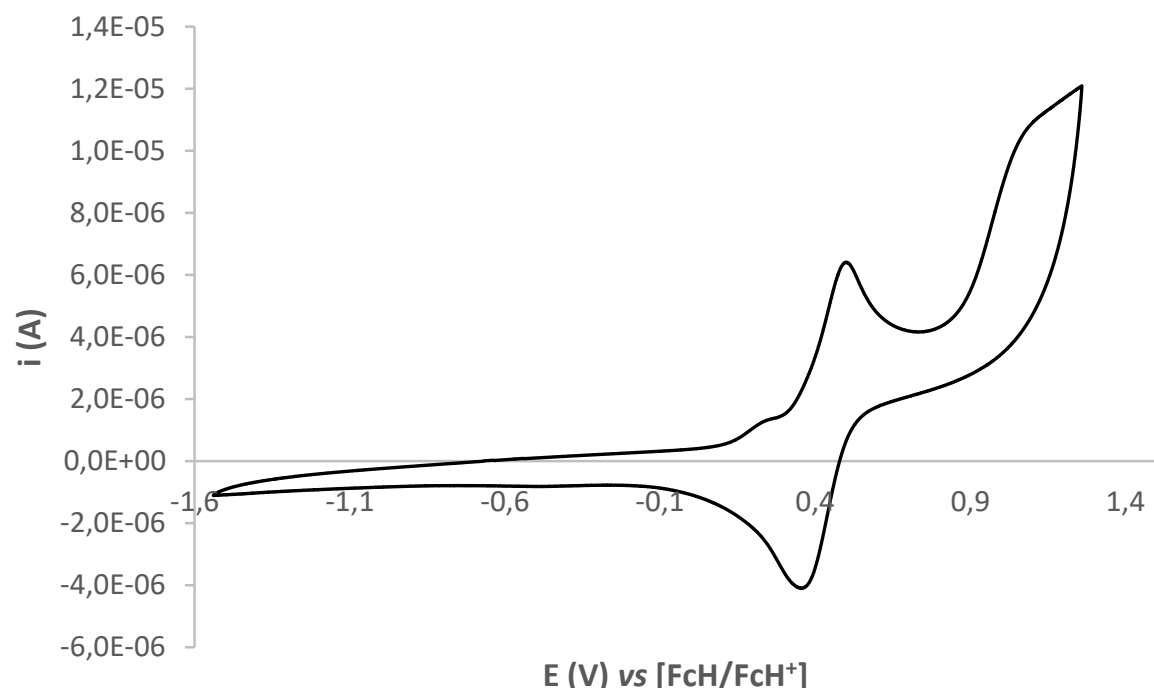

Figure 3. Cyclic voltammogram on a Pt electrode of complex 2: $1 \mathrm{mM}$ in $\mathrm{CH}_{2} \mathrm{Cl}_{2}$ with $n \mathrm{Bu}_{4} \mathrm{NBF}_{4}(0.1 \mathrm{M})$ at a scan rate of $0.2 \mathrm{~V} \mathrm{~s}^{-1}$.

Although it was possible to generate the oxidised complexes by bulk electrolysis, we ruled this procedure out for preparative purposes since it could be difficult to separate the 
expected product from the ionic supporting electrolyte. We thus turned to chemical oxidation. The choice of oxidant was guided by the $E_{1 / 2}$ values of the ferrocene/ferrocenium redox couple, obtained via electrochemical methods, but other parameters had to also be taken into account, such as the "innocent" character of the reagent and the ease of purification of the oxidised Rh complex [30]. $\mathrm{NOBF}_{4}$ is a strong oxidant but reacted with the phosphine group, giving a phosphine oxide. $\mathrm{AgBF}_{4}$ was the most obvious choice, however its oxidation potential is very solvent-dependent and should perform the oxidation of the ferrocenyl moiety in $\mathbf{1}$ and $\mathbf{2}$ in $\mathrm{CH}_{2} \mathrm{Cl}_{2}\left(\mathrm{E}^{\circ}=0.65 \mathrm{~V} /\left[\mathrm{FcH} / \mathrm{FCH}^{+}\right]\right)$, but not in a coordinating solvent like $\mathrm{MeCN}\left(\mathrm{E}^{\circ}=0.04 \mathrm{~V} /\left[\mathrm{FCH} / \mathrm{FcH}^{+}\right]\right)$. We therefore focused our attention on thianthrenium tetrafluoroborate $[\mathrm{Th}]\left[\mathrm{BF}_{4}\right]\left(\mathrm{E}^{\circ}=0.86 \mathrm{~V} /\left[\mathrm{FcH} / \mathrm{FcH}^{+}\right]\right.$in $\left.\mathrm{MeCN}\right)$, the oxidation potential of which does not vary much with the solvent [22]. [Th][BF 4 gives deep purple solutions in acetonitrile and is insoluble in ether, whereas its reduced form is colourless and soluble in ether. This means that the reactions can be followed visually and that the oxidised rhodium complexes may be purified by simple precipitation and washing with $\mathrm{Et}_{2} \mathrm{O}$.

\section{Chemical oxidation of complexes $\mathbf{1}$ and $\mathbf{2}$ in dichloromethane}

Complex 1 was oxidised in $\mathrm{CH}_{2} \mathrm{Cl}_{2}$, either by addition of solid, anhydrous $\mathrm{AgBF}_{4}$ [31], or by a $[\mathrm{Th}]\left[\mathrm{BF}_{4}\right]$ solution in the same solvent at room temperature (scheme 2 ). The orange dichloromethane solution turned rapidly olive-green, at which point it was concentrated to ca. $0.5 \mathrm{~mL}$, and diethyl ether was added. A dark green precipitate separated from the light yellow solution, which was filtered off. The green solid was further rinsed with diethyl ether and analysed by ${ }^{1} \mathrm{H}$ and ${ }^{31} \mathrm{P} \mathrm{NMR}$ in $\mathrm{CD}_{2} \mathrm{Cl}_{2}$ (fig. 4).
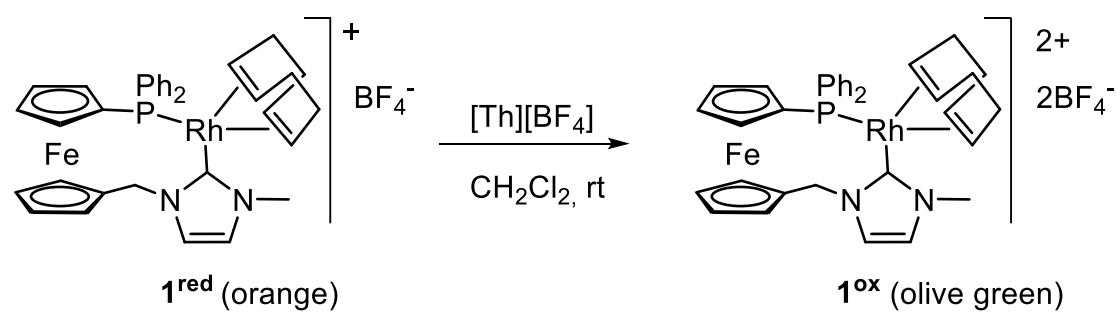

Scheme 2. Oxidation of rhodium(I) complex 1 with [Th] $\left[\mathrm{BF}_{4}\right]$ in $\mathrm{CH}_{2} \mathrm{Cl}_{2}$. 
5h30 after addition of $\mathrm{H}_{2} \mathrm{O}$

(excess)

45 min after addition of $\mathrm{H}_{2} \mathrm{O}$

(excess)

45 min after addition of $[\mathrm{Th}]\left[\mathrm{BF}_{4}\right]$

(1.5 equiv.)

complex x

$\begin{array}{lllllllllllllllllllllllllll}190 & 180 & 170 & 160 & 150 & 140 & 130 & 120 & 110 & 100 & 90 & \begin{array}{c}80 \\ \mathrm{f} 1(\mathrm{ppm})\end{array} & 60 & 50 & 40 & 30 & 20 & 10 & 0 & -10 & -20 & -30 & -40 & -5\end{array}$

Figure 4. ${ }^{31} \mathrm{P}$ NMR spectra: oxidation of complex 1 by $[\mathrm{Th}]\left[\mathrm{BF}_{4}\right]$ in $\mathrm{CD}_{2} \mathrm{Cl}_{2}$.

The ${ }^{1} \mathrm{H}$ NMR spectrum showed very broad signals stretching from $\delta 25$ to -10 , whereas no or very weak shifted signals were detected by ${ }^{31} \mathrm{P}$ NMR. The characteristic colour and the absence of ${ }^{31} \mathrm{P}$ NMR signal suggested to us that we had generated paramagnetic ferrocenium. The reversible nature of this oxidation was demonstrated when excess water was added to the green $\mathrm{CD}_{2} \mathrm{Cl}_{2}$ solution [32]: the solution became orange again and its ${ }^{31} \mathrm{P}$ NMR spectrum showed a doublet at $\delta 19.5$ with a coupling constant of $158 \mathrm{~Hz}$. Purification of the NMR sample by simple drying and filtration on neutral alumina allowed the complete recovery of the starting $\mathrm{Rh}(\mathrm{I})$ complex.

It has been demonstrated by Wrighton et al. that infra-red $v_{c o}$ values in transition metal carbonyl complexes with ferrocenylphosphino ligands could be increased by up to $20 \mathrm{~cm}^{-1}$ upon oxidation of ferrocene [11]. More recently, Bielawski et al. measured the values for a carbonyl rhodium complex bearing a diaminocarbene-ferrocenophane ligand in both reduced and oxidised states, and found on average a difference of $20 \mathrm{~cm}^{-1}$ between the two oxidation states [33]. Infra-red thus appeared to us as a powerful tool to demonstrate the influence of ferrocene oxidation state on the electron density at rhodium in our complexes. In a typical procedure, solid, anhydrous $\mathrm{AgBF}_{4}$ (1.5 equiv.) was used to generate the oxidised form of carbonyl complex 2 in $\mathrm{CH}_{2} \mathrm{Cl}_{2}$ (scheme 3). The colour turned in a few seconds from light yellow to forest green [34]. 


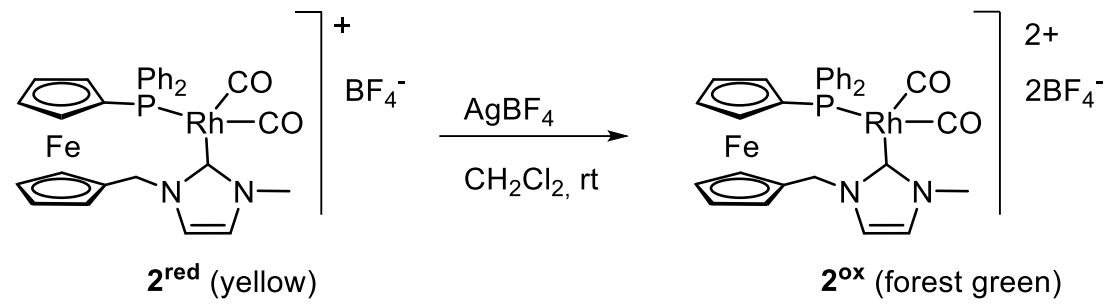

Scheme 3. Oxidation of rhodium(I) carbonyl complex 2 with $\mathrm{AgBF}_{4}$ in $\mathrm{CH}_{2} \mathrm{Cl}_{2}$.

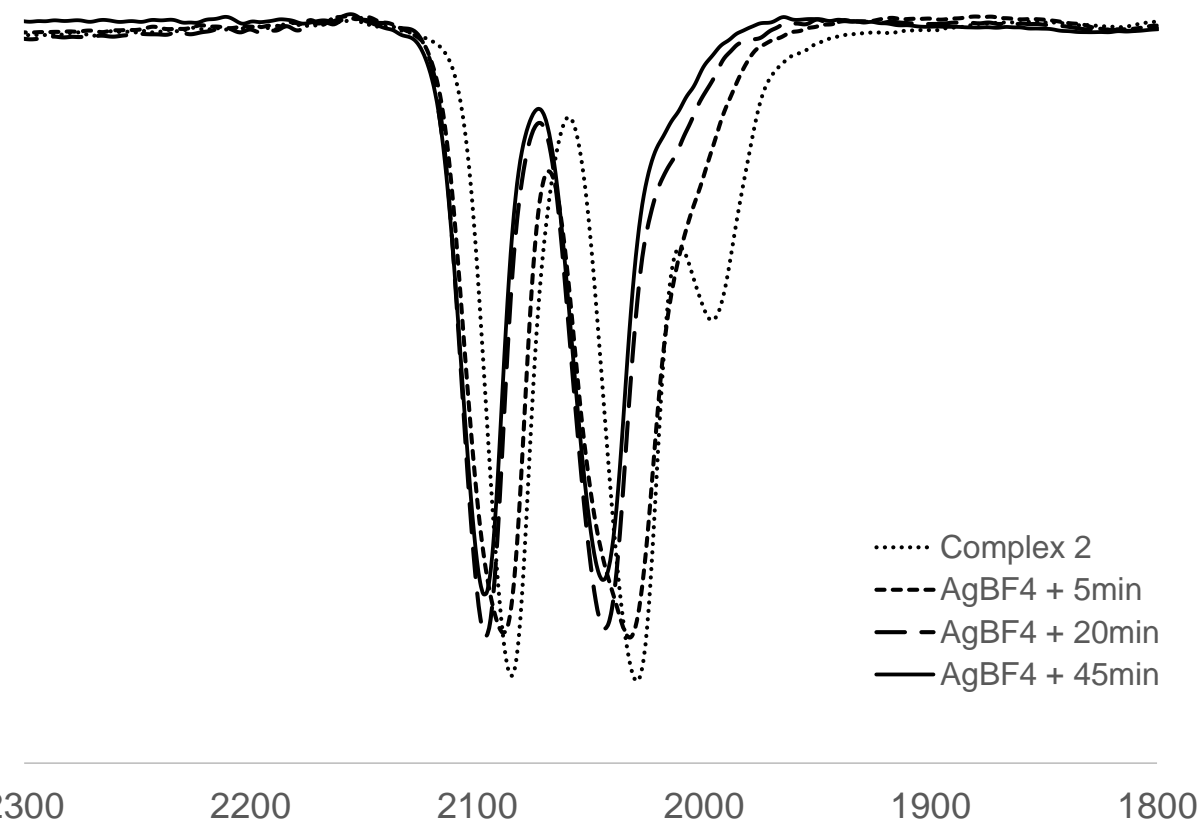

Figure 5. IR spectra (ATR), oxidation of complex 2 with $\mathrm{AgBF}_{4}$ in $\mathrm{CH}_{2} \mathrm{Cl}_{2}$. $v$ co $\left(2^{\text {red }}\right), \mathrm{cm}^{-1}$ : 2084, 2029; after 45min, $v_{c o}\left(2^{\circ x}\right), \mathrm{cm}^{-1}: 2097,2045$. The small band at $1997 \mathrm{~cm}^{-1}$ for the initial solution is attributed to a monocarbonyl impurity (see Experimental section).

IR spectra were taken at intervals and showed the shift of the original $v_{\text {co }}$ bands to higher stretching frequencies by $13 \mathrm{~cm}^{-1}$ for the higher frequency band and by $16 \mathrm{~cm}^{-1}$ for that at lower frequency (fig. 5) [35]. This is characteristic of a metal centre with a lower electron density, since decreased backbonding from the $d$-orbital of the metal to the $\pi^{*}$ antibonding orbital strengthens the $\mathrm{CO}$ bonds and shifts the $v_{\mathrm{cO}}$ bands toward higher frequencies. The average difference between the $v_{c o}$ values for $2^{\text {red }}$ and $\mathbf{2}^{\text {ox }}$ is $14 \mathrm{~cm}^{-1}$, which is significant enough to assert that the reactivity at the rhodium centre may be affected by the oxidation of the ferrocene unit.

\section{Chemical oxidation of complexes 1 and $\mathbf{2}$ in acetonitrile}

As $\mathrm{AgBF}_{4}$ has a redox potential of $0.04 \mathrm{~V} /\left[\mathrm{FcH} / \mathrm{FcH}^{+}\right]$in $\mathrm{MeCN}$ [29], it should not be capable of oxidizing the ferrocene moiety of $\mathbf{2}$. We therefore turned to [Th][BF 4 , which possesses the additional advantage of being very soluble in this solvent. Typically, a solution of 
[Th] $\left[\mathrm{BF}_{4}\right]$ in MeCN was added dropwise to a solution of complex 2 in the same solvent (scheme 4). As reported earlier in the case of 1, we observed a very different behaviour from the reaction in dichloromethane: no colour change to green was detected. Rather, a brownorange solution was obtained after the addition of ca. 1.5 equivalent of oxidant. At the end of the addition, the solvent was evaporated to a minimum and diethyl ether was added to precipitate the rhodium complex and wash off the products of $\left[\mathrm{Th}^{2}\left[\mathrm{BF}_{4}\right]\right.$ reduction as well as unreacted 2.

The ${ }^{31} \mathrm{P}$ NMR spectrum of the crude reaction mixture showed one major species appearing as a doublet at $\delta 41.5$, with a coupling constant of $138 \mathrm{~Hz}$, along with some unreacted 2, whereas the ${ }^{1} \mathrm{H}$ NMR spectrum was typical of a diamagnetic compound, and revealed the presence of bound acetonitrile molecules. We demonstrated earlier, for the oxidation of $\mathbf{1}$ in acetonitrile, that the species showing a doublet at $\delta 41.5$ is a rhodium(III) complex resulting from the oxidation of the ferrocene unit to ferrocenium and subsequent electron transfer from rhodium to ferrocenium [21]. The reorganisation of the coordination sphere around rhodium to adopt the preferred octahedral geometry implied coordination of acetonitrile molecules. An unusual $\mathrm{C}-\mathrm{H}$ activation at ferrocene followed this reorganisation to give the air-stable rhodium(III) complex 3 . Here we demonstrate that the oxidations of complex 1 (bearing a COD ligand) and the dicarbonyl complex 2 lead to the same species (scheme 4). The full characterization of the product $\mathbf{3}$, which includes the X-ray diffraction analysis of a bipy derivative, is reported in our previous contribution [21].
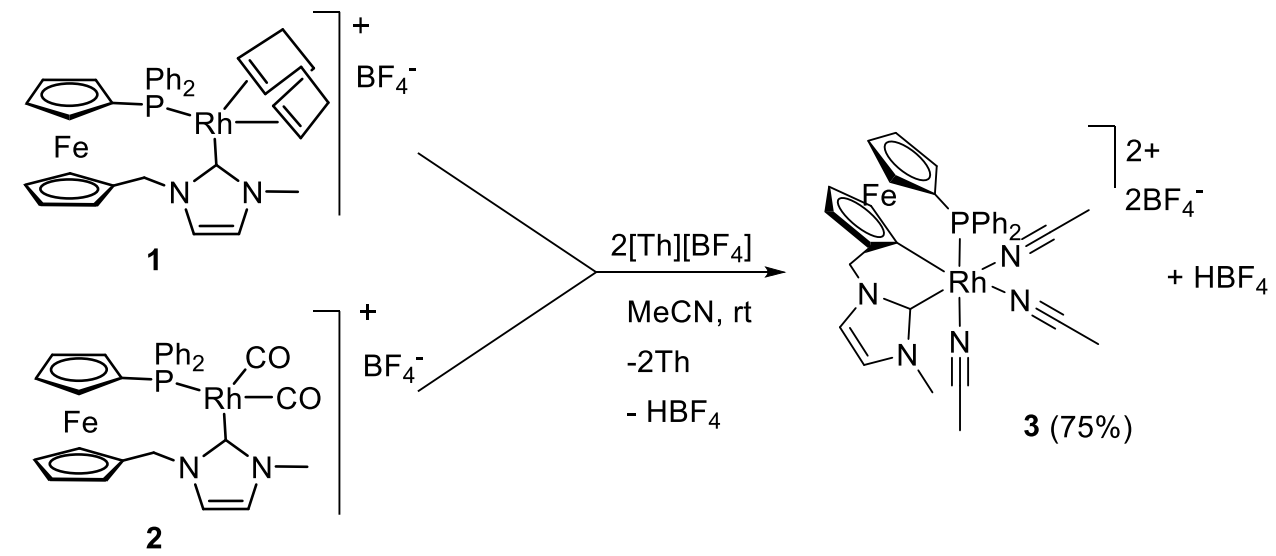

Scheme 4. Oxidation of complexes 1 and $\mathbf{2}$ with $\left[\mathrm{Th}^{\mathrm{T}}\left[\mathrm{BF}_{4}\right]\right.$ in $\mathrm{MeCN}$.

The reaction of the carbonyl complex 2 was also followed by ${ }^{31} \mathrm{P}$ NMR (fig. 6). The species giving a doublet at $\delta 28.7$ was previously shown to be the intermediate rhodium(III) species (4) that has not yet undergone the $\mathrm{C}-\mathrm{H}$ activation at ferrocene (scheme 5): it was the main species observed after $10 \mathrm{~min}$, along with some unreacted 2 and an unidentified by-product at $\delta c a$. 25. Oxidation of rhodium(I) to rhodium(III) is thus very quick and is followed by the slow $\mathrm{C}-\mathrm{H}$ activation at ferrocene to give complex 3 as the main species after $24 \mathrm{~h}$. 


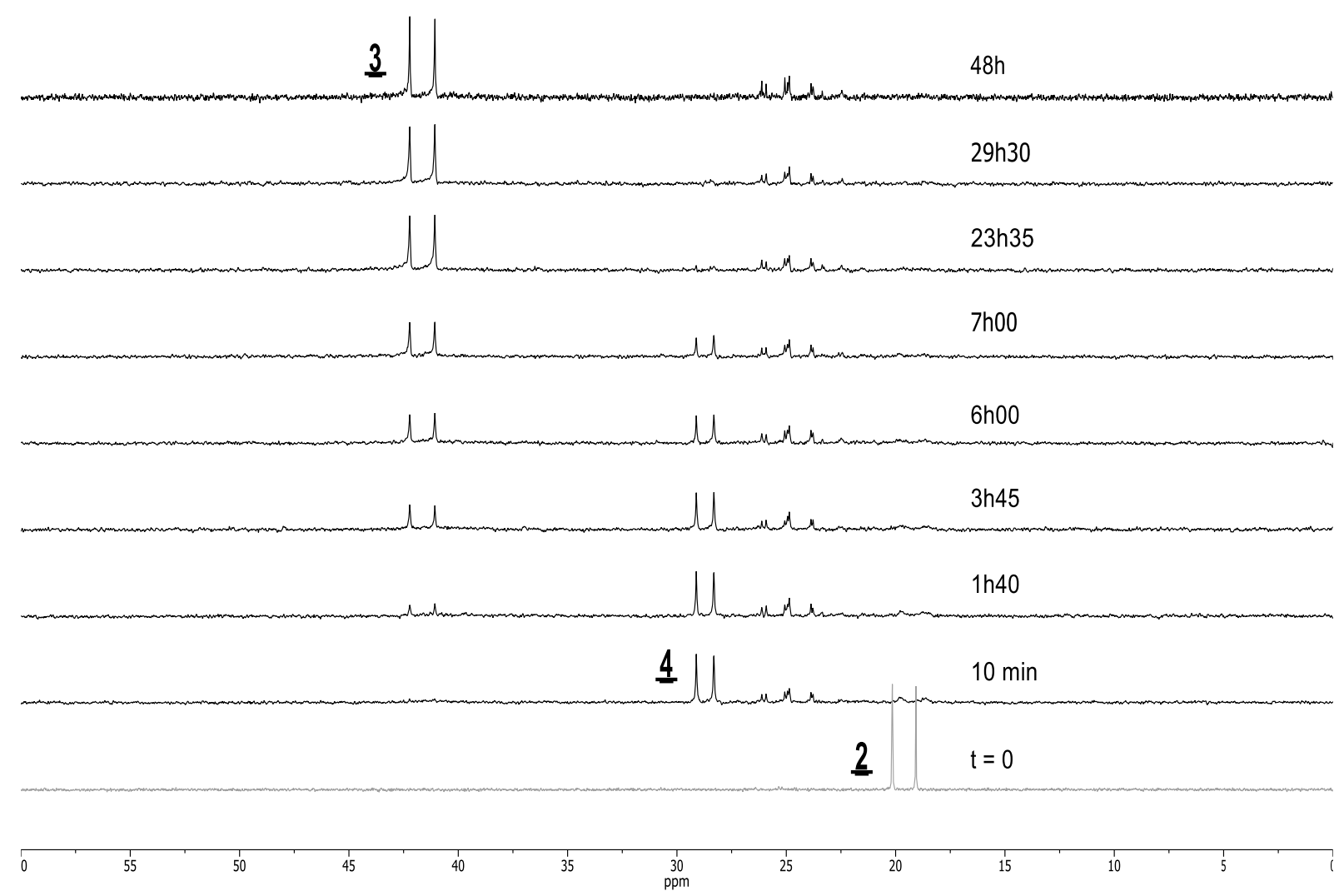

Figure 6. ${ }^{31} \mathrm{P}$ NMR spectra: oxidation of complex 2 by $\left[\mathrm{Th}^{2}\right]\left[\mathrm{BF}_{4}\right]$ in $\mathrm{MeCN}$.
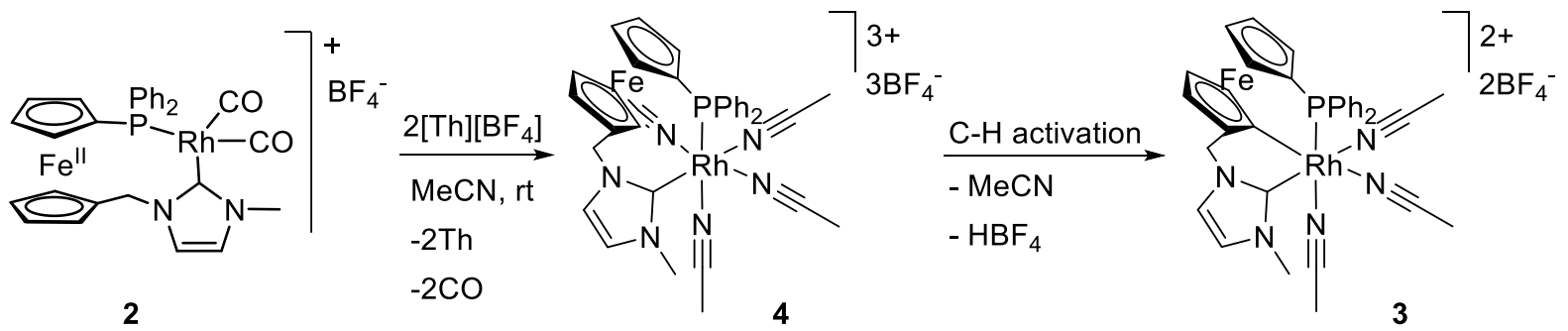

Scheme 5. Intermediate species (4) in the oxidation process of $\mathrm{Rh}^{\prime}$ complex $\mathbf{2}$ to $\mathrm{Rh}^{\mathrm{III}}$ complex $\mathbf{3}$.

In order to check that ferrocene could efficiently act as an electron relay, complex $\mathbf{2}$ was first oxidized in $\mathrm{CH}_{2} \mathrm{Cl}_{2}$ with an excess of $\mathrm{AgBF}_{4}$ (1.5 equiv.), giving rise to the forest-green, paramagnetic ferrocenium- $\mathrm{Rh}(\mathrm{I})$ complex $\mathbf{2}^{\mathbf{0 x}}$ (scheme 6). After filtration of insoluble silver, the solution was evaporated in vacuo to give a green solid: upon addition of MeCN, the colour instantly turned to orange-brown. After $24 \mathrm{~h}$ standing at room temperature, the solvent was evaporated and the orange residue analysed by ${ }^{31} \mathrm{P}$ and ${ }^{1} \mathrm{H} N M R$. The ${ }^{31} \mathrm{P} N M R$ spectrum revealed the presence of two species in $c a$. 75:25 ratio: the doublet situated at $\delta$ $41.6\left(J_{\mathrm{Rh}-\mathrm{P}}=138 \mathrm{~Hz}\right)$, characteristic of complex 3 , and a doublet at $\delta 33.2\left(J_{\mathrm{Rh}-\mathrm{p}}=120 \mathrm{~Hz}\right)$ that might arise from the reaction of $2^{\text {red }}$ with acetonitrile. The ${ }^{1} \mathrm{H}$ NMR spectrum confirmed the presence of complex $\mathbf{3}$ as the main product. The product distribution is consistent with the oxidation stoichiometry (two oxidizing equivalents are necessary to convert $\mathbf{2}^{\text {red }}$ to $\mathbf{3}$ ). 


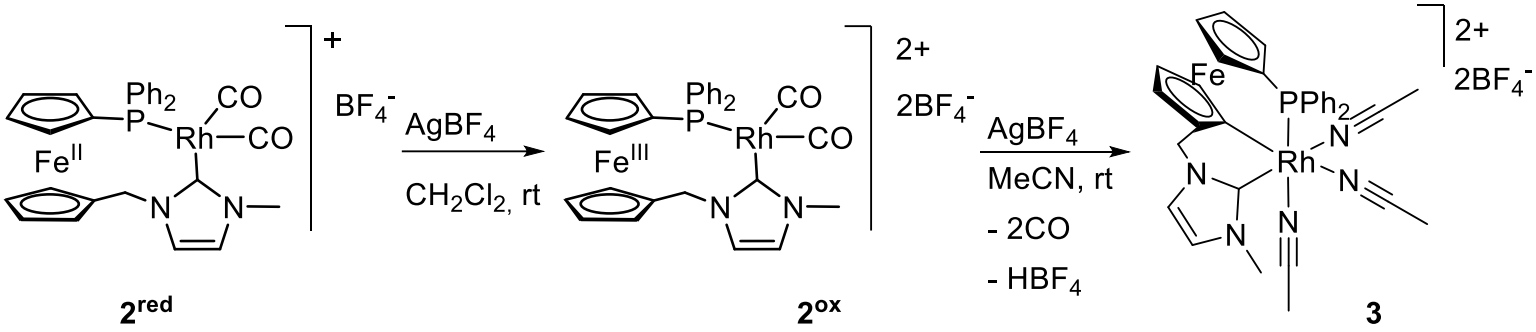

Scheme 6. Stepwise oxidation of complex 2 in $\mathrm{CH}_{2} \mathrm{Cl}_{2}$ and reaction of $\mathbf{2}^{\mathrm{ox}}$ in $\mathrm{MeCN}$.

The above combined results confirm that the reactivity of the rhodium centre can be enhanced dramatically, simply by changing the oxidation state of a ligand electronically connected to Rh. Thanks to this stepwise process and to the irreversible character of the reaction, it even becomes possible to use $\mathrm{AgBF}_{4}$, a very common and convenient oxidant which is too weak to operate in acetonitrile.

\section{Hydrosilylation catalysis}

Rhodium(III) complexes, particularly half-sandwich $\mathrm{Rh}^{\text {III }}$ complexes, are catalysts of choice for the functionalization of $\mathrm{C}_{\mathrm{sp2} 2} \mathrm{H}$ bonds [36-38] and we recently showed the potential of complex $\mathbf{3}$ for this type of reaction [21]. We envisioned that this system may also be suitable for other types of catalytic reactions, such as the hydrosilylation of carbonyl compounds. We previously described the use of complex 1 and its analogue bearing a norbornadiene ligand in place of COD as catalysts for this reaction but both proved rather sluggish, probably due to their high stability and the difficulty to remove the diene ligand [17].

Thus hydrosilylation of acetophenone and its derivatives were carried out with $1 \mathrm{~mol} \%$ of complex 1 or $\mathbf{3}$ in THF at room temperature (scheme 7, table 2). All reactions were stopped after $17 \mathrm{~h}$ to allow for direct comparison of conversions.

Scheme 7, Table 2. Hydrosilylation of acetophenone derivatives.

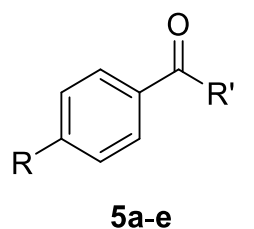

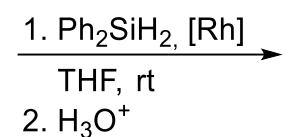

2. $\mathrm{H}_{3} \mathrm{O}^{+}$<smiles>[R]c1ccc(C([R])O)cc1</smiles>

\begin{tabular}{|l|l|c|c|c|}
\hline \multirow{2}{*}{ Entry } & \multirow{2}{*}{ Substrate (R, $\left.\mathrm{R}^{\prime}\right)$} & \multirow{2}{*}{ Product } & \multicolumn{2}{|c|}{ Conversion (\%) (b) } \\
\cline { 4 - 5 } & & & Complex 1 & Complex 3 \\
\hline 1 & $\mathbf{5 a}(\mathrm{H}, \mathrm{Me})$ & $\mathbf{6 a}$ & $54(1)$ & $85(4)$ \\
\hline 2 & $\mathbf{5 b}(\mathrm{Me}, \mathrm{Me})$ & $\mathbf{6 b}$ & $43(4)$ & $88(3)$ \\
\hline 3 & $\mathbf{5 c}(\mathrm{OMe}, \mathrm{Me})$ & $\mathbf{6 c}$ & $53(3)$ & $90(1)$ \\
\hline 4 & $\mathbf{5 d}(\mathrm{F}, \mathrm{Me})$ & $\mathbf{6 d}$ & $50(0)$ & $78(4)$ \\
\hline 5 & $\mathbf{5 e}\left(\mathrm{H}_{1} \mathrm{CF}_{3}\right)$ & $\mathbf{6 e}$ & $>99$ & $>99$ \\
\hline
\end{tabular}


(a) Reagents and conditions: acetophenone (1.0 equiv., 2M in THF), diphenylsilane (1.1 equiv.), Rh cat. (1mol\%), rt, 17 h. (b) Average of two runs, with \% difference between the two runs in parentheses; conversion calculated by integration of characteristic ${ }^{1} \mathrm{H}$ NMR signals of acetophenone derivative and 1-phenylethanol derivative in the crude reaction mixture after hydrolysis of the silyl ether.

As a general observation, the rhodium(III) complex 3 shows good activity for the hydrosilylation of both electron-rich and electron-deficient acetophenones and is a better catalyst than the rhodium(I) complex 1 . The reaction of diphenylsilane with acetophenone was followed by ${ }^{1} \mathrm{H}$ NMR in $\mathrm{d}_{8}$-THF. The conversion of acetophenone into the expected silyl ether was plotted against time and the reaction profiles turned out surprisingly different for 1 and 3 (fig. 7) [39]. Comparison of the initial rates shows that the catalytic activity of $\mathbf{3}$ is 20 times greater than that of $\mathbf{1}$. For complex $\mathbf{1}$, the reaction follows a first order rate law, whereas the data for $\mathbf{3}$ do not appear consistent with a simple rate law.

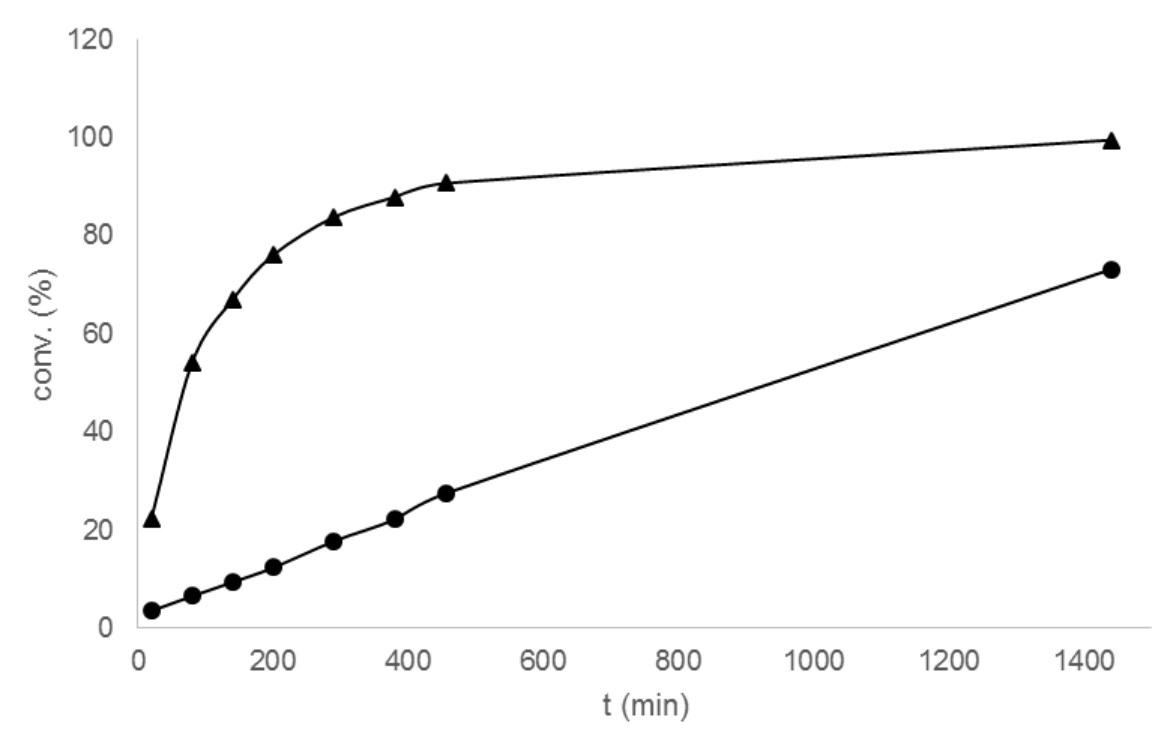

Figure 7. Reaction of $\mathrm{Ph}_{2} \mathrm{SiH}_{2}$ with acetophenone (1 mol\% catalyst, $\mathrm{d}_{8}-\mathrm{THF}, \mathrm{rt}$ ). Conversion (\%) of acetophenone vs. time, circles: complex 1; triangles: complex 3.

\section{Conclusions}

A new dicarbonyl rhodium(I) complex bearing an electroactive ferrocenyl phosphine-NHC ligand has been synthesized and fully characterized. Its behaviour in the presence of a chemical oxidant has been studied, proving that the electron density at the rhodium centre could be tuned by oxidation of the ferrocenyl group on the bidentate ligand. This difference has been highlighted by infra-red spectroscopic measurement of the CO stretching frequencies. The dicarbonyl rhodium(I) complex has also shown an interesting reactivity in acetonitrile which parallels that of the related COD complex $\mathbf{1}$, giving a stable rhodium(III) 
complex after several oxidation-electron transfer processes and complete reorganisation of the coordination sphere.

\section{Acknowledgements}

This work was supported by the Agence Nationale de la Recherche (ANR-07-JCJC-0041). We are also grateful to the CNRS (Centre National de la Recherche Scientifique) for further financial support.

\section{Appendix A. Supplementary Data}

CCDC 986640 contains the supplementary crystallographic data for compound 2 . This data can be obtained free of charge via http://www.ccdc.cam.ac.uk/conts/retrieving.html, or from the Cambridge Crystallographic Data Centre, 12 Union Road, Cambridge CB2 1EZ, UK; fax: +44 1223-336-033; or e-mail: deposit@ccdc.cam.ac.uk. Supplementary data associated with this article: crystal data and refinement parameters for compound $\mathbf{2}$. 


\section{References}

1. I.M. Lorkovic, M.S. Wrighton, W.M. Davis, J. Am. Chem. Soc., 116 (1994) 6220-6228.

2. C.S. Slone, C.A. Mirkin, G.P.A. Yap, I.A. Guzei, A.L. Rheingold, J. Am. Chem. Soc., 119 (1997) 10743-10753.

3. C.K.A. Gregson, V.C. Gibson, N.J. Long, E.L. Marshall, P.J. Oxford, A.J.P. White, J. Am. Chem. Soc., 128 (2006) 7410-7411.

4. K. Arumugam, C.D. Varnado, S. Sproules, V.M. Lynch, C.W. Bielawski, Chem.-Eur. J., 19 (2013) 10866-10875.

5. C.D. Varnado, Jr, E.L. Rosen, M.S. Collins, V.M. Lynch, C.W. Bielawski, Dalton Trans., 42 (2013) 13251-13264.

6. A.G. Tennyson, V.M. Lynch, C.W. Bielawski, J. Am. Chem. Soc., 132 (2010) 9420-9429.

7. E.M. Broderick, N. Guo, T. Wu, C.S. Vogel, C. Xu, J. Sutter, J.T. Miller, K. Meyer, T. Cantat, P.L. Diaconescu, Chem. Commun., 47 (2011) 9897-9899.

8. E.M. Broderick, N. Guo, C.S. Vogel, C. Xu, J. Sutter, J.T. Miller, K. Meyer, P. Mehrkhodavandi, P.L. Diaconescu, J. Am. Chem. Soc., 133 (2011) 9278-9281.

9. M. Süßner, H. Plenio, Angewandte Chemie International Edition, 44 (2005) 6885-6888.

10. R. Savka, S. Foro, M. Gallei, M. Rehahn, H. Plenio, Chem.- Eur. J., 19 (2013) 10655-10662.

11. T.M. Miller, K.J. Ahmed, M.S. Wrighton, Inorg. Chem., 28 (1989) 2347-2355.

12. A.M. Allgeier, C.S. Slone, C.A. Mirkin, L.M. Liable-Sands, G.P.A. Yap, A.L. Rheingold, J. Am. Chem. Soc., 119 (1997) 550-559.

13. I.V. Kourkine, C.S. Slone, C.A. Mirkin, L.M. Liable-Sands, A.L. Rheingold, Inorg. Chem., 38 (1999) 2758-2759.

14. I.M. Lorkovic, R.R. Duff Jr., M.S. Wrighton, J. Am. Chem. Soc., 117 (1995) 3617-3618.

15. D.A. Weinberger, T.B. Higgins, C.A. Mirkin, L.M. Liable-Sands, A.L. Rheingold, Angew. Chem. Int. Ed., 38 (1999) 2565-2568.

16. K.J. Blackmore, J.W. Ziller, A.F. Heyduk, Inorg. Chem., 44 (2005) 5559-5561.

17. A. Labande, J.-C. Daran, E. Manoury, R. Poli, Eur. J. Inorg. Chem., (2007) 1205-1209.

18. J. Wolf, A. Labande, J.-C. Daran, R. Poli, Eur. J. Inorg. Chem., (2007) 5069-5079.

19. N. Debono, A. Labande, E. Manoury, J.-C. Daran, R. Poli, Organometallics, 29 (2010) 18791882.

20. A. Labande, J.-C. Daran, N.J. Long, A.J.P. White, R. Poli, New J. Chem., 35 (2011) 2162-2168.

21. A. Labande, N. Debono, A. Sournia-Saquet, J.-C. Daran, R. Poli, Dalton Trans., 42 (2013) 65316537.

22. B. Boduszek, H. J. Shine, J. Org. Chem., 53 (1988), 5142-5143.

23. A. Altomare, M. Burla, M. Camalli, G. Cascarano, C. Giacovazzo, A. Guagliardi, A. Moliterni, G. Polidori, R. Spagna, J. Appl. Cryst., 32 (1999) 115-119.

24. G. M. Sheldrick, Acta Cryst. A, 64 (2008) 112-122.

25. L. J. Farrugia, J. Appl. Cryst., 30 (1997) 565.

26. L.D. Field, B.A. Messerle, K.Q. Vuong, P. Turner, Organometallics, 24 (2005) 4241-4250.

27. L.D. Field, B.A. Messerle, K.Q. Vuong, P. Turner, Dalton Trans., (2009) 3599-3614.

28. S. Burling, L.D. Field, H.L. Li, B.A. Messerle, P. Turner, Eur. J. Inorg. Chem., 2003 (2003) 31793184.

29. C.H. Leung, C.D. Incarvito, R.H. Crabtree, Organometallics, 25 (2006) 6099-6107.

30. N.G. Connelly, W.E. Geiger, Chem. Rev., 96 (1996) 877-910. 
31. The quality of $\mathrm{AgBF}_{4}$ is crucial since only traces of water lead to the reduction of ferrocenium.

32. $\mathrm{H}_{2} \mathrm{O}$ reduces ferrocenium back to ferrocene in complex 1 but the nature of the oxidized species was not investigated yet.

33. D.M. Khramov, E.L. Rosen, V.M. Lynch, C.W. Bielawski, Angew. Chem. Int. Ed., 47 (2008) 2267-2270.

34. $\mathbf{2}^{\mathrm{ox}}$ is very sensitive to moisture and turned rapidly from forest green to brown when exposed to traces of water to give a complex mixture.

35. The third band of medium intensity at $1997 \mathrm{~cm}^{-1}$ may be attributed to the monocarbonyl complex due to an incomplete reaction ( ${ }^{31} \mathrm{P}$ NMR: $>95 \%$ of dicarbonyl complex in this sample).

36. D.A. Colby, R.G. Bergman, J.A. Ellman, Chem. Rev., 110 (2010) 624-655.

37. J. Wencel-Delord, T. Droge, F. Liu, F. Glorius, Chem. Soc. Rev., 40 (2011) 4740-4761.

38. G. Song, F. Wang, X. Li, Chem. Soc. Rev., 41 (2012) 3651-3678.

39. The amount of silyl enol ether by-product was neglected in the calculations since it represents less than $1 \%$ of the total. 